\title{
Educação musical nas escolas brasileiras: Retrospectiva histórica e Tendências pedagógicas atuais
}

Teresa da Assunção Novo Mateiro

\section{Breve Retrospectiva Histórica}

No Brasil, a educação musical passou por uma trajetória lenta e reformista, observando-se as mais diversas concepções referentes ao ensino da música. Por exemplo, com a queda do sistema Republicano em 1930, instalou-se uma política educacional nacionalista e autoritária que utilizou a música para desenvolver a "coletividade", a "disciplina" e o "patriotismo". É durante esse período que se dá a obrigatoriedade do ensino de música nas escolas primárias e secundárias (Decreto $\mathrm{n}^{\circ} 19891$, de 11 de abril de 1931), refletindo um momento de transformação liderado por Villa-Lobos. A esse respeito cita-se o pensamento de Souza (1992):

"a idéia sobre a educação musical na literatura dos anos trinta é muito diferenciada e por vezes contraditória. Especialmente são colocados objetivos sócio-políticos muito gerais como educação musical a serviço da coletividade e unidade nacional, o despertar do sentimento de brasilidade ou ainda disciplina social, que no entanto não são em lugar algum claramente definidos mas apenas vagamente descritos" (p.13).

Após a Segunda Grande Guerra, surge o movimento Música Viva, liderado por HansJoachim Koellreuter, o qual defendia o "combate 
pela música que revela o eternamente novo, isto é: por uma arte musical que seja a expressão real da época e da sociedade". Este movimento foi apoiado por uma importante geração de compositores brasileiros, entre os quais Cláudio Santoro, César Guerra Peixe, Edino Krieger, Heitor Alimonda e Eunice Katunga, que posteriormente seguiriam caminhos diversos.

O movimento Música Viva teve também sua participação na educação musical brasileira. Ressaltam-se aqui os pontos essenciais: (a) o privilégio da criação musical; (b) a importância da função social do criador contemporâneo; (c) a questão do coletivo; (d) a contemporaneidade e renovação (KATER, 1992). De excertos (transcritos por Kater) do capítulo "Da educação artística, de uma mentalidade nova, de um novo estilo" do Manifesto de 1945, extrai-se parte do pensamento do Grupo Música Viva referente ao ensino de música:

"1. educar a coletividade utilizando as inovações técnicas a fim de que ela se torne capaz de selecionar e julgar o que de melhor se adapta à personalidade de cada um dentro das necessidades da coletividade; 2 . combater 0 ensino baseado em opiniões pré-estabelecidas e preconceitos aceitos como dogmas; 3 . reorganizar os meios de difusão cultural. (...) Consideramos essencial a substituição do individualismo e do exclusivismo pelo coletivismo em música, preconizamos para o ensino musical as formas coletivas de ensino: canto orfeônico e conjunto instrumental" (Ibid, p.24-5).

Depois de diversas práticas influenciadas por "movimentos educacionais e estéticos, demonstrando práticas rígidas e flexíveis, 
especializadas e integradas, unimetódicas e ecléticas, tradicionais e inovadoras" (OLIVEIRA, 1992, p.38), a educação musical brasileira nos anos 60 viveu tendências que ressaltavam a sensibilidade, criação e improvisação. Discute-se o que é sensibilizar e musicalizar e afirmam-se palavras-chave como Iniciação Musical, Musicalização, Arte-Educação, Sensibilização, Métodos.

Em 1971, a música passou a fazer parte de um ensino interdisciplinar, com base no artigo $7^{\circ}$ da Lei 5692 de 1971. Com esta reforma, a Educação Artística foi introduzida nos currículos escolares de I e II Graus, trazendo problemas para o ensino da música, bem como para as outras artes (artes plásticas e artes cênicas). A partir de 1971, o professor de Educação Artística ficou responsável por uma prática pedagógica polivalente. Conseqüentemente, aqueles profissionais que tinham formação na área da música davam aulas de música e, esporadicamente, pincelavam tentativas com atividades de artes plásticas e artes cênicas. Entretanto, aqueles professores que não tinham formação em música acabavam ministrando aulas apenas nas outras áreas.

Por outro lado, os cursos de Licenciatura em Educação Artística ofereciam disciplinas nas três áreas, disto resultando uma aprendizagem rápida e superficial. Vale ressaltar que a maioria dos alunos que ingressava nesses cursos não possuía nenhuma formação prévia em qualquer das áreas, criando-se assim um "exemplo típico de um círculo vicioso: o aluno não possui educação musical a nível de I e II Graus, conseqüentemente chega nas graduações sem muito conhecimento prévio, e retorna como professor sem muitas condições de desenvolver 
um ensino apropriado de música" (HENTSCHKE, 1993, p.52). Depois de formado, o professor procura fazer o concurso público que, de acordo com a Lei $\mathrm{n}^{\circ} 5692 / 71$, the permite ministrar aulas apenas da $5^{\text {a }}$ à $8^{\text {a }}$ série do I Grau ou no II Grau. Dessa forma, as séries primárias foram as primeiras a ficar sem professor especializado e, de um modo geral, o ensino de música nas escolas parece estar desaparecendo gradualmente.

A educação musical tornou-se, então, privilégio de uns poucos, pois a maioria das escolas brasileiras aboliu o ensino de música dos currículos escolares devido a fatores como a não-obrigatoriedade da aula de música na grade curricular e a falta de profissionais da área, somando-se a isso os valores culturais e sociais que regem a sociedade brasileira. As raras instituições de ensino que ainda preservam a música no programa curricular oferecem uma carga horária mínima e, nessa situação caótica, ainda encontra-se a problemática da prática pedagógica da educação musical (BEYER, 1993). $\mathrm{Na}$ grande maioria das vezes, segundo Santos (1994), as aulas restringem-se ao trabalho de "eventos culturais objetivando culminâncias que, embora altamente motivadoras, vêm em nome de um produto, sacrificando um processo" (p.10). E a autora prossegue mencionando que os professores aceitam a função de "festeiro, preparador de hinos; encaram o trabalho artístico e musical como auxiliar pedagógico para fixação de conhecimentos de outras disciplinas; justificam o trabalho artístico e musical como momento de liberação emocional e/ou relaxamento para o desenvolvimento em processos cognitivos desenvolvidos em outras disciplinas do currículo" (lbid). 
Nesse sentido, é pertinente o pensamento de Tourinho (1993b): "vista como uma 'mera' disciplina, a música não é tratada como um tipo de conhecimento a ser ensinado, estudado, compreendido e recriado" (p.68). Mas por outro lado, continua a autora, a música está sempre presente nos rituais do ambiente escolar, seja nas festas e celebrações, seja na "organização e validação do tempo e do espaço das ações que acontecem no dia-a-dia escolar" (Ibid., p.69).

Esta situação, sem dúvida, reflete os valores ideológicos e filosóficos que a educação musical possui para a nossa sociedade. Educação, cultura, arte tornaram-se superficialidades, e apenas aqueles com condições financeiras para pagar professores particulares de música (mais especificamente de um instrumento musical) ou de qualquer outra área têm acesso a outras modalidades de conhecimento. Segundo Hentschke (1993b), essa atitude que privilegia uma pequena parte da população brasileira, "contradiz todo e qualquer princípio educacional" (p.52).

Outro aspecto a ser considerado, além da ineficiente formação dos professores, é a falta de embasamente teórico que fica explícita em suas práticas, 0 que promoveria 0 direcionamento a uma filosofia pedagógica. É comum, por parte dos professores, a procura de atividades prontas, as famosas 'receitas'. As aulas limitam-se a uma seqüência de atividades escolhidas a esmo ou então adota-se algum método gerado no Brasil (Villa-Lobos, Gazzi de Sá, Liddy Mignone e Sá Pereira) ou algum método trazido da Europa - o que é o mais comum - (Dalcroze, Orff, Kodaly, Willems, Martenot), métodos estes que por muito tempo serviram, e ainda servem, de modelo na prática 
educacional. A esse respeito, cita-se a contribuição de Penna (1990):

"No entanto, não podemos esquecer que esses métodos carregam uma concepção de música e de mundo. Podemos nos reapropriar de exercícios dos vários métodos, na condição de, compreendendo os princípios que os embasam, redirecioná-los para as metas que almejamos. 0 problema, afinal, é não tomar esses métodos como um conjunto de técnicas a reproduzir, consagradas pela assinatura de seu autor, e portanto capazes de garantir, em todos os níveis, a nossa prática. Nem a prática nem qualquer método devem estar imunes a questionamentos, que são, inclusive, o motor de um constante aprimoramento" (p.66).

Observa-se ainda o crescente número de materiais pedagógicos. Começa a aparecer uma variedade de livros didáticos para os mais diversos instrumentos, bem como para a Educação Musical. Entre eles, citam-se, por exemplo: "Meu Piano é Divertido" (1976); "Explorando Música através do Teclado" (1989); "Iniciação Musical com Introdução ao Teclado" (1990); "Criando e Aprendendo" (1973); "Pedrinho Toca Flauta: uma iniciação musical através da flauta doce para crianças" (1985).

Os livros surgem como uma estratégia de melhoria da qualidade de ensino, como um mecanismo de modernização ao invés da modificação de planos e programas de estudo. A esse processo, Torres (1994) chama de "tecnologia educativa" e, além de falar sobre o aspecto positivo dos livros no rendimento escolar, a autora posiciona-se da seguinte maneira: "(...) a maior participação docente e a maior autonomia pedagógica que hoje se 
reivindica para os professores, resgatando seu papel técnico e profissional, contradiz essencialmente a dependência, cada vez maior, do livro escolar como resposta às suas fraquezas" (p.24).

Apesar de Torres (1994) referir-se ao livro escolar em especial, sua posição é bastante pertinente e adequada também ao professor de música, assim como se pode observar através do pensamento de Santos (1994): "a ênfase no tratamento do ensino musical através da experimentação gerou a fase do livro didático, em que a 'experimentação' do fenômeno musical é prevista passo a passo" (p.10). Esse procedimento didático é observado tanto na prática dos professores de instrumento quanto na dos professores de educação musical.

Os professores de instrumento escolhem determinados livros e durante anos tendem a repetir as mesmas estratégias de ensino, o mesmo repertório. De acordo com Santiago (1994), existe nesses professores "uma tendência à acomodação aos processos por meio dos quais eles próprios foram educados, sem uma exploração de novos métodos". E a autora continua: "ocorre inclusive uma acomodação ao repertório padrão, e ouvem-se dezenas de alunos a repetirem as mesmas obras anos após anos, como se só aquelas existissem fomentando um 'mesmismo' generalizado" (p.226). Por outro lado, o professor de educação musical reproduz atividades extraídas de métodos, assim como afirma Santos, ao comentar a experiência musical brasileira nos últimos anos:

"Foi imediata a adoção de séries de exercícios com o fim de facilitar a aprendizagem de elementos expressivos da linguagem musical 
(embora desligados de um fazer próprio do grupo, da forma de organização da linguagem no novo contexto sócio-cultural), exercícios esses isentos de dimensão estética e musical, que fragmentam a experiência artística destituindo-a de unidade e sentido. (...) Pouca ou nenhuma reflexão ocorreu sobre os pressupostos filosóficos e psicológicos desses métodos, as bases sócio-culturais sobre as quais foram construídos ou sua abrangência como experiência pedagógica" (1994, p.10).

\section{Tendências Pedagógicas Atuais}

Apesar de no Brasil haver uma carência de estudos que tratem da prática da educação musical em sala de aula, pode-se afirmar que existem linhas filosóficas educacionais por vezes não declaradas que estão diretamente relacionadas à ação pedagógica dos professores. De acordo com Libâneo (1987), "uma boa parte dos professores, provavelmente a maioria, baseia sua prática em prescrições pedagógicas que viram senso comum, incorporadas quando de sua passagem pela escola ou transmitidas pelos colegas mais velhos; entretanto, essa prática contém pressupostos teóricos implícitos" (p.19).

Fonterrada (1993), ao analisar a situação da música no Brasil a partir de 1971, lembrando as modificações estruturais que ocorreram com - ensino da música nas escolas, ressalta que duas linhas pedagógicas podem ser identificadas, as quais a autora denomina de 'tradicional' $e$ 'alternativa'. A tradicional, segundo Fonterrada, "aproxima-se do modelo de educação tecnicista e tem por objetivo a formação de instrumentistas, cantores, compositores e/ou 
regentes" (p.78). Os profissionais que seguem essa linha defendem a música como privilégio somente daqueles bem dotados musicalmente, importam valores e procedimentos de outros países sem refletir sua adequação para o ensino brasileiro, enfim, cultivam um passado, tendo dificuldades de acompanhar as novas propostas que surgem na área.

A educação musical 'alternativa', conseqüência da prática da Educação Artística, advoga a música como uma prática de todos, amparando-se nos pressupostos filosóficos da corrente pedagógica ativa, ou seja, centrada na iniciativa e nos interesses dos alunos. Inserida num modelo teórico naturalista, a prática educacional da música, assim como assinala Fonterrada (1993), ressalta a "ampliação do universo sonoro, expressão musical através da vivência e da experimentação livre, liberação das emoções, valorização do folclore e da música nacional" (p.79).

As duas linhas pedagógicas - tradicional e alternativa - detectadas por Fonterrada (1993) assemelham-se às linhas mencionadas por Swanwick (1988) quando o autor se refere às teorias de educação musical identificadas nas escolas inglesas. A linha pedagógica tradicional fundamenta-se nos mesmos princípios da teoria também denominada de tradicional, enquanto que a alternativa corresponde à teoria progressista, ambas concebidas com as mesmas características.

$\mathrm{Na}$ Inglaterra, com o intuito de verificar cuidadosamente a prática musical curricular, foi realizado, por Swanwick (1988), um estudo em 60 escolas, entre 1985 e 1987. O pesquisador pôde detectar uma grande variedade de 
atividades em sala de aula, as quais pareciam ser determinadas pelos princípios teóricos e pedagógicos de cada professor. Não existia, portanto, continuidade e sistematização na prática curricular do ensino de música nas instituições de ensino.

A partir da diversidade de propostas de aprendizagem realizadas nas aulas de música, Swanwick (1988) verificou que tais atividades poderiam ser classificadas em "três bases lógicas rivais", quais sejam: a 'tradicional' ou 'centrada na matéria', a 'progressista' ou 'centrada na criança' e a 'multicultural'. Essas teorias que tentam classificar as correntes pedagógicas na prática escolar têm sido utilizadas, por muitos pedagogos, como instrumento de análise da prática docente. São fundamentadas nas teorias de educação já existentes.

A teoria tradicional de educação caracteriza-se pelo predomínio do ensino dirigido, onde o professor transmite ao aluno informações, consideradas apropriadas, referentes a determinados assuntos, os quais devem ser memorizados. Cabe ao professor a seleção do que, como e quando o aluno vai aprender, bem como a seleção do material pedagógico. Não se questiona o porquê de tal aprendizagem. "Os conteúdos, os procedimentos didáticos, a relação professor-aluno não têm nenhuma relação com o cotidiano do aluno e muito menos com as relações sociais. É a predominância da palavra do professor, das regras impostas, do cultivo exclusivamente intelectual" (LIBÂNEO, 1987, p.22).

No ensino da música predominam atividades como o desenvolvimento da leitura da notação musical, a aprendizagem de habilidades 
específicas para tocar um instrumento e informações acerca das 'melhores músicas' e dos 'melhores compositores' dos diferentes períodos da história da música. Em geral, ocorre um ensino fragmentado, sem que exista uma relação entre os assuntos estudados, ou seja, existe uma desvinculação bastante significativa entre a teoria e a prática. A abordagem adotada está relacionada à psicologia 'mecanicista' (ou psicologia associacionista, em vigor no século passado), onde a preocupação está centrada no resultado, não no processo que ocorre durante a aprendizagem (BIGGE, 1977).

Em contraposição à teoria tradicional, a progressista valoriza a auto-educação, preocupando-se mais com os processos mentais e habilidades cognitivas do que com a organização racional dos conteúdos (LIBÂNEO, 1987). O ensino é centrado no aluno e no grupo, ressaltando-se o desenvolvimento das aptidões individuais. Volta-se para a compreensão da natureza psicológica da criança, pois suas necessidades e interesses são importantes para que ela se adapte com facilidade ao meio. 0 professor agora tem o papel de auxiliar o desenvolvimento livre e espontâneo da criança, atentando também para manter um relacionamento positivo com o aluno.

Vários educadores musicais desenvolveram idéias semelhantes, baseadas nesses princípios educacionais, as quais podem ser observadas com freqüência na prática educacional dos professores de música tanto de escolas inglesas quanto de escolas americanas. Carl Orff, o primeiro pedagogo progressista (Swanwick, 1988), enfatizou a participação efetiva do aluno através de sua experiência na execução de instrumentos musicais, canto, treinamento 
auditivo, movimento e improvisação. Defendeu a prática antes da teoria, não se preocupando com a segunda questão. Para Orff, a música é o resultado natural da fala, do ritmo e do movimento, estabelecendo-se assim a tríplice aliança artística, igualmente almejada por ele música, dança e drama (CHOSKY et al., 1986) 0 importante é a criança vivenciar, fazer música dentro de um grupo até criar suas próprias manifestações sonoras e ir tomando consciência de conjunto a cada etapa do processo.

$\mathrm{Na}$ mesma linha filosófica, cita-se também John Paynter na Grã-Bretanha, Murray Schafer no Canadá e, nos Estados Unidos, o Programa Curricular de Música Manhattanville (1970), planejado por Ronald Thomas (SWANWICK, 1988). John Paynter e Murray Schafer enfatizam o trabalho de composição como base para a educação musical nas escolas. Estes autores defendem o desenvolvimento da criatividade através da exploração e organização de qualquer material sonoro (PAYNTER, 1970; SCHAFER, 1967). A obra de Paynter, assim como a de Schafer, descreve inúmeras experiências obtidas em sala de aula, resultando num material de sugestões para professores. Contudo, Schafer (1991) faz uma advertência em relação à sua obra, dizendo que esta "é um relato pessoal de um educador musical e não o enunciado de um método para a imitação submissa" (p.14).

Por sua vez, o Programa Curricular de Música Manhattanville (1970) enfoca três aspectos principais que, de alguma forma, também estavam presentes no trabalho de Paynter e Schafer. São eles: (a) a relevância artística, ou seja, música como arte; (b) a relevância pessoal, considerando a relação das necessidades musicais dos alunos com a 
satisfação das mesmas; (c) a relevância social, focando a cultura, o meio e as mudanças passíveis de ocorrer ao longo do processo de movimento da sociedade.

A orientação para o ensino de música, durante as décadas de 60 e 70 na Inglaterra e nos Estados Unidos, fundamenta-se, portanto, no desenvolvimento da criatividade, da experimentação e da auto-expressão, alcançadas através de atividades de improvisação e composição. Nesse processo, o trabalho centrase quase que exclusivamente na manipulação e experimentação dos mais diferentes materiais, utilizando-se desde o som de papéis, plásticos, vidros, enfim, material de sucata em geral, até o som de sintetizadores e computadores. Ao professor compete orientar o aluno, facilitando o processo de aprendizagem, "estimulando, questionando, aconselhando e auxiliando, ao invés de demonstrar e dizer" (SWANWICK, 1988, p.14).

A terceira teoria da educação musical citada por Swanwick (1988) é a teoria multicultural, a qual, segundo o autor, está relacionada à diversidade cultural encontrada nas sociedades, resultante tanto do crescimento da migração e imigração das mais diversas culturas quanto do desenvolvimento dos cada vez mais eficientes meios de comunicação. Não há dúvida de que as preferências musicais são sinais culturais, e os processos de rotular a música e de colocá-la dentro de um contexto de aprovação social são universais e podem ser encontrados dentro de qualquer categoria de tradições ocidentais clássicas ou folclóricas. Conseqüentemente, a fusão da música com a cultura e o estilo de vida em geral dá-se de acordo com os costumes culturais óbvios, ou 
seja, costumes e práticas religiosas, políticas ou de qualquer outra categoria (Ibid.,1988).

De acordo com a linha de pensamento multicultural, o papel da educação é evitar, ou pelo menos reduzir, a rotulação e a estereotipação cultural através de um maior contato com diferentes manifestações musicais, fazendo com que os alunos vivenciem experiências construídas a partir de elementos independentes de vinculação cultural. A principal tarefa do professor refere-se à escolha do repertório. Conforme Swanwick (1988), o educador tem a responsabilidade de tornar familiares aos estudantes as diferentes convenções estruturais presentes nos diversos idiomas musicais, ou seja, mostrar como as idéias musicais podem ser estabelecidas e transformadas através dos diversos modos de repetição e contraste.

Hentschke (1993므) entende que, além das três bases educacionais expostas até aqui, ainda uma outra está presente na ação pedagógica dos professores de música, a qual a autora denomina de Teoria Psicológica (p.62) e que se refere aos processos cognitivos envolvidos na aprendizagem do pensamento musical. Desde o final do século passado educadores musicais e psicólogos vêm pesquisando como a música é processada pelo indivíduo e que efeitos psicológicos exerce sobre ele (lbid., p.63). Por outro lado, poucos estudos foram realizados sobre 0 desenvolvimento musical relativamente ao crescimento físico e intelectual do indivíduo. Uma das tentativas mais recentes é a Teoria Espiral de Desenvolvimento Musical de Keith Swanwick (1988), que enfoca a maneira pela qual ocorre o conhecimento e a compreensão musicais em cada indivíduo. 0 autor propõe uma seqüência 
específica referente ao desenvolvimento musical da criança, adolescente ou adulto. Hentschke (1993b) reforça a posição de Swanwick observando que o Modelo Espiral pode servir de "suporte para o desenvolvimento curricular" e também como "critério para avaliação dos produtos musicais" (p.64).

Uma prática educacional baseada nos princípios da Teoria Psicológica, segundo Hentschke (1993므), deverá preocupar-se com "os processos cognitivos, idade psicológica da criança, e o que ela é capaz de aprender, musicalmente falando, de acordo com sua idade mental, psicomotora e afetiva" (p.64). Um currículo estruturado dessa forma propiciaria melhores condições de aprendizagem musical, pois estaria em conformidade com 0 desenvolvimento físico e psicológico da criança.

Além da abordagem pedagógica, outros fatores adicionam-se ao contexto das aulas de música nas escolas brasileiras. Fala-se da carga horária reduzida que é oferecida para o ensino da música. Na maioria das escolas que oferecem aulas de música, estas são ministradas uma vez por semana num período que varia de quarenta minutos a uma hora. Não há dúvida que esse intervalo de tempo é insuficiente para que se realize um trabalho sólido e consistente. Outro fator importante são os recursos materiais adequados - espaço físico, instrumentos musicais, aparelho de som, computador, entre outros - para desenvolver-se um trabalho diversificado. Conforme Swanwick (1994), as aulas de música estão muito aquém dos avanços tecnológicos do século XX. Discos, rádio, televisão, computadores, instrumentos musicais (teclados eletrônicos, por exemplo) proporcionam mais recursos para o acesso à 
música de todos os tipos e lugares. Fora da escola as práticas musicais crescem em função da tecnologia de sons materiais, apresentando uma grande diversidade, desde a música experimental, minimalista, até a música popular., Dentro das escolas, ao contrário, parece que a prática musical está baseada em escalas pentatônicas e sons que aparentemente não fazem parte da vida dos alunos.

A partir da exposição feita até aqui, constata-se a preocupação, não só no Brasil mas também em outros países, com os princípios teóricos e pedagógicos que regem o ensino da música nas escolas. No Brasil, a reflexão e o debate sobre o tema aumentam de importância em razão da falta de planejamento e sistematização, dois aspectos que têm sido insuficientes na formação musical dos alunos. Da mesma forma, a luta para que a música seja uma matéria fundamental e obrigatória no currículo escolar das escolas brasileiras tem sido tema de discussão nos Encontros Nacionais de Educadores Musicais.

\section{Conclusão}

Refletindo-se sobre a situação da educação musical no Brasil, verifica-se que vários são os fatores que impedem a formação de uma sociedade musicalmente educada. Inicialmente, ressalta-se o fato do ensino de música não ser obrigatório nas escolas, sendo que, em consequiência, apenas algumas escolas, em geral as particulares, mantêm professores especializados. No ano de 1987, Hentschke (1993므) realizou uma pesquisa em 148 escolas de 6 municípios do estado do Rio Grande do Sul e detectou que $89 \%$ das instituiçõos de ensino não 
oferecia educação musical. Acredita-se que essa situação repete-se nas demais regiões do país. Conclui-se, portanto, que a maioria dos estudantes, quando termina o II Grau, não têm conhecimentos musicais básicos, o que acarreta uma sociedade de pessoas incapazes de analisar e selecionar criticamente as músicas que se apresentam no contexto cultural da sociedade moderna.

A formação dos professores é um outro aspecto, sobre o qual pode-se verificar que não existem modelos de referência única, mas, ao contrário, o que há é uma formação que se tornou multifária e pluralista, muito embora persistam referências básicas de preparação técnica e de exigências ética e educacional. 0 certo, porém, é que a sempre crescente complexidade do ensino da música em nosso tempo, bem como a dificuldade de compreensão das relações sociais e dos comportamentos humanos diante dos valores em transformação, as linhas filosóficas, sociológicas e psicológicas que permeiam o sistema educacional compõem um conjunto de fatores que torna o exercício da função de educador musical sempre mais difícil, não se justificando assim, em hipótese alguma, confiar esse múnus a quem não possua efetiva preparação profissional. Dessa forma, os professores devem procurar realizar uma reflexão crítica permanente, bem como acompanhar as mudanças no sistema educacional e as novas manisfestações musicais.

Como já discutido anteriormente, o quadro de referência das aulas de música é, sem dúvida, um fator que interfere diretamente na formação do indivíduo e, conseqüentemente, reflete o perfil do sistema educacional. Partindo do que foi analisado até aqui, pode-se dizer 
através das palavras de Beyer (1993) que a "falta de continuidade é outra deficiência no ensino de música. A prática da educação musical está desarticulada, inexiste a idéia da construção de uma seqüência com um fio condutor em sua essência" (p.16). Assim, os profissionais da área têm sentido a necessidade de uma maior estruturação curricular que possa sistematizar a efetivação de uma prática de educação musical coerente.

No Brasil, a elaboração e implantação de currículos de educação musical geralmente fica restrita a repartições de ensino específicas, sem que haja a divulgação de tais trabalhos. Daí que, apesar de existirem trabalhos nesse sentido, pode-se dizer que não existem currículos-base publicados que orientem a ação pedagógica dos educadores musicais, algo que pode ser observado na prática de outros países. Como Tourinho (1995) constata: "não existe um levantamento de dados sobre onde, como, sob que orientação e programa este ensino acontece" (p.39). Registra-se, portanto, a necessidade da sistematização do ensino de música nas escolas brasileiras através de programas curriculares correspondentes e adequados aos mais diversos fatores que interferem no sistema escolar. 


\section{Referências bibliográficas}

BEYER, Esther. A Educação Musical sob a Perspectiva de uma Construção Teórica: uma análise histórica. Fundamentos da Educação Musical, Porto Alegre, p.5-25, maio 1993.

BIGGE, Morris L. Teorias da Aprendizagem para Professores. São Paulo: E.P.U., 1977. 370p.

CHOSKY, L.; ABRANSOM, R.; GILLEPIE, A. Et al. Teaching Music in the Twenty Century. New Jersey: Prentice-Hall, Inc., 1986. 343p.

FONTERRADA, Marisa. A Educação Musical no Brasil - Algumas Considerações, Anais - II Encontro Anual: ABEM, Porto Alegre, p.69-83, maio 1993.

-.... Música, Conhecimento e História: um exercício de contraponto. Anais $1^{\circ}$ Encontro Anual: ABEM, Porto Alegre, p.4757, dez 1992.

HARGREAVES, David J. Teoria e Prática em Educação Musical: uma Perspectiva Britânica, Anais - $1^{\circ}$ Encontro Anual: ABEM, Porto Alegre, p.12-23, dez 1992. Trad. Diana Santiago.

HENTSCHKE, Liane. A Adequação da Teoria Espiral como Teoria de Desenvolvimento Musical. Fundamentos da Educação Musical, Porto Alegre, n.1, p.47-70, maio 1993. Relações da Prática com a Teoria na Educação Musical. Anais - II Encontro Anual da ABEM, Porto Alegre, p.49-67, maio 1993b.

KATER, Carlos. Aspectos Educacionais do Movimento Música Viva. Revista da ABEM, n.1, Ano I, p.22-34, maio 1992. 
LIBÂNEO, José Carlos. Democratização da escola Pública: A Pedagogia Crítico-Social dos Conteúdos. $5^{\mathrm{a}}$ ed. São Paulo: Loyola, 1987. 149p.

OLIVEIRA, Alda de Jesus. A Educação Música No Brasil: ABEM. Revista da ABEM, n.1, Ano I, p.3540, maio 1992.

PAYNTER, John. Sound and Silence: classroom projects in creative music. Cambridge:

Cambridge University Press, 1970.

PENNA, Maura. Reavaliações e Buscas em Musicalização. São Paulo: Loyola, 1990. 85p.

SANTOS, Regina M. S. A Natureza da Aprendizagem Musical e suas Implicações Curriculares - análise comparativa de quatro métodos. Fundamentos da Educação Musical, Porto Alegre, p.7-112, junho 1994.

. Repensando o Ensino de Música. Cadernos de Estudo: Educação Musical, Belo Horizonte, p.31-52, agosto 1990.

SANTIAGO, Diana. Processos da Educação Musical Instrumental, ANAIS - III Encontro Anual da ABEM, Salvador, p. 215-31 junho 1994.

SOUZA, Jusamara. Funções e Objetivos da Aula de Música Vistos e Revistos Através da Literatura dos Anos Trinta. Revista da ABEM, n.1, Ano I, p.12-21, maio 1992.

SWANWICK, Keith. A Basis for Music Education. London: Routledge, 1979, 122p.

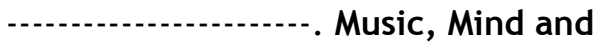

Education. London: Routledge, 1988, 161p. Musical Knowledge: Intituion Analysis and Music Education. London: Routledge, 1994. 
Permanecendo Fiel à

Música na Educação Musical. ANAIS - II Encontro da ABEM, Porto Alegre, p.19-32, maio 1993.

Trad. Diana Santiago.

TOURINHO, Irene. Usos e Funções da Música na Escola Pública de $1^{\circ} \mathrm{Grau}$. Fundamentos da

Educação Musical, Porto Alegre, n.1, p.91-133, maio 1993.

- Música e Controle: necessidade e utilidade da música nos ambientes ritualísticos das instituições escolares, Em Pauta, Porto Alegre, p.67-78, 1993ㅁ․

TORRES, Rosa María. Que (e como) é necessário aprender? Campinas: Papirus, 1994. Trad. Talia Bugel. 158p. 